Jahrbuch der

Heinrich-Heine-Universität

Düsseldorf

2007/2008

$\mathbf{d}|\mathbf{u}| \mathbf{p}$ 



\title{
Jahrbuch der Heinrich-Heine-Universität Düsseldorf 2007/2008
}

\author{
Herausgegeben vom Rektor \\ der Heinrich-Heine-Universität Düsseldorf \\ Univ.-Prof. Dr. Dr. Alfons Labisch
}

Konzeption und Redaktion:

Univ.-Prof. em. Dr. Hans Süssmuth

$\mathrm{d}|\mathbf{u}| \mathbf{p}$ 


\section{(cc) BY-NC-ND}

This work is licensed under the Creative Commons Attribution-NonCommercial-NoDerivs 4.0 License. For details go to http://creativecommons.org/licenses/by-nc-nd/4.0/.

C C düsseldorf university press, Düsseldorf 2008

Einbandgestaltung: Wiedemeier \& Martin, Düsseldorf

Titelbild: Schloss Mickeln, Tagungszentrum der Universität

Redaktionsassistenz: Georg Stüttgen

Beratung: Friedrich-K. Unterweg

Satz: Friedhelm Sowa, LATE $_{\mathrm{E}}$

Herstellung: Uniprint International BV, Meppel, Niederlande

Gesetzt aus der Adobe Times

ISBN 978-3-940671-10-3

eISBN 978-3-11-071883-6 